\title{
Religions and Laïcité in the French Republican School
}

\author{
Alessandro Bergamaschi and Catherine Blaya
}

\section{1 \\ Introduction}

The status of religion in Western societies is an issue that constantly comes to the fore in European public debates, especially when the issue is to "go beyond the ordinary, or that regarding social dysfunctions and incidents"1 (Campiche, 2010: 27). Despite the current relevance of these debates, whenever the question of the capacity of religion to impact daily life is raised, "the hidden assumptions are often found in a narrative of loss - loss of privilege, loss of authority, perhaps loss of vitality and influence" (Ammerman, 2010: 155). This loss of influence appears to be confirmed by various European surveys, especially concerning young people (Lambert, 2000; Galland, 2008, 2009). In any case, a counterweight to the steadily declining influence of religion on individual lives can be observed in the widespread popularity of certain social issues which, either directly or indirectly, question the institutions of religion. In France, the most vivid debate is about wearing visible religious symbols in public spaces or about school lunch specific menus, mainly within schools. This apparent paradox is likely based on the assumption that modernity doesn't allow enough space for religion to act as a means for interpreting reality. Yet closer examination backs up the idea to deal the thesis about the loss of influence cautiously. Even Berger (1999) didn't seem particularly convinced that the impact of religion on daily life was likely to decline inexorably, though he did uphold the hypothesis of its relegation to protected enclaves in order to ensure that it would overcome the effects of the continuing process of rationalization.

The present chapter questions the status of religion in contemporary French society. Throughout the chapter, religion is conceived as a transversal dimension of the constitution of French society. We will see that although it is strongly characterized by the opposite phenomenon, namely secularism, religion

1 All the translations are made by the authors.

(C) ALESSANDRO BERGAMASCHI AND CATHERINE BLAYA, 2020 | DOI:10.1163/9789004429604_025

This is an open access chapter distributed under the terms of the GC BY-NG-NPd 4co license B Blaya - 9789004429604 
"exerts its impact both actively and passively, explicitly or implicitly, in every corner of social, cultural and psychological reality" (Hervieu-Leger, 1999: 19).

First, we focus on the relationship between religion and French society. We lay out that the foundation of the principle of secularism is the cornerstone of the French social and political philosophy and its ambition is to be a key element of social cohesion. Then, as this ideological architecture needs a specific actor to be implemented, the following paragraph is devoted to the role played by the school system. We highlight the role of the education system as an actor in charge of the socialization to the Republican creed, widely based on the principle of secularism. The second part of this chapter presents findings from a survey completed in several secondary schools in the South of France. This survey about the factors of social cohesion among teenagers, shows that religious belonging is related to the school experiences and the feeling to belong to the French national community.

\section{The Separation of Church and State and the Implementation of Secularism in France}

Secularism is a key element of the institutional and political dimensions of French society and has been used as a model for public space management since the French Revolution. This was later strengthened under the Third Republic $\left(1875^{-1940)}\right)$. At that time, religion was considered as some kind of enemy for two different reasons. First, it claimed to have the monopoly of social knowledge throughout the entire nation or even at a universal level. This was unbearable for the spirits from the Age of Enlightenment (18th century) since France is a nation of which culture was built upon a strong contribution from the intellectual class -namely Auguste Comte and Emile Durkheim- who have worked long and hard to design the core values of the nation that would be freed from the legacies of religion and that should be transmitted and disseminated through the education system. As characterized by the French sociologist, Durkheim (1858-1917) schools are to fulfil a socialization role and teach the children, future of the nation, the way they should behave as citizens in accordance with the rules and norms of the society as a whole. As a consequence, education was a key element of the ideological state apparatus. On the other hand, fears regarding religion were fed by religious authorities who attempted to set up constituencies of local authorities through their diocese and parishes. Aristocrats and revolutionaries were at the roots of suspicion towards any form of local association that were considered as potentially plotting against the project of one dominant national culture at that time. As such, Church and its leadership and convening capacities at the local level could be 
perceived as a potential counter-power and as the bastion of reaction. This historical background leads to the designing of secularism over three aspects:

a) the fight against the monopoly of Church over knowledge;

b) the setting up of a dominant collective culture of which ethics would not be informed by religion;

c) the strong will for the country to be ruled and the decision power to be held by one actor, the government, and to not be shared with religious authorities, simultaneously neutralizing any local specificity (Duru-Bellat, van Zanten, 2012).

The 1905 law performed a complete separation of Church and State but also set up the principles of freedom of conscience and freedom to exercise any faith. Church was to remain outside any political activity at the national level. This law officialized that schools were to become free from any religious influence and education was about the inculcation of Enlightenment principles and dominated by the collective culture of the French nation in search of unity.

There was a return to religion after the establishment of the July Monarchy in 1830 and a controversy over the freedom of education in 1843 rooting in the 1830 Charte that opened up the possibility of the creation of "public instruction and freedom of education". In 1833, Guizot designed a law including the possibility to create publicly funded elementary schools that could be run by the Church and the creation of Church primary and secondary schools. At that time, secondary schools were not under the supervision of the State. Ten years later, the Church claimed the right for "freedom of education" in secondary education, that is the right of parents to choose the school of their children (private, religious or state schools) and to offer national qualifications. They lost their claim and it was not until 1848 that the Falloux law restored some of the power that the Church had over secondary education and exempted religious schools from delivering state certifications.

The Third Republic was paramount in the creation of modern French society and the strengthening of the Republican ideals, among which the transfer of religious issues into the private sphere. If Church had been marginalized, the education system did not fully manage to offer education to masses and it was not until the end of the nineteenth century that there was a genuine impetus on popular education when primary schooling became compulsory for all. Tensions between the supporters of state education -the new Republican elite- and those of private education, that is anti-Republicans, started to emerge over the content of textbooks. These tensions lasted until after the second world war, when the State became the one actor of the democratization of education and secularism entered the French constitution in 1946. Since the 
year 1959, the two systems (state education and private religious education) have co-existed, and there has been an increase in state-subsidized private Catholic schools. The private and state system tend to be seen as complementary, since the State has recognized the private education sector as a "private service for public utility", as stressed by Tanguy (1972), considering that private schools are often used as "second chance" schools by parents of students at risk of dropping out (Ballion, 1986).

Although secular education remains dominant, the partisans of secularism have grown less inflexible since the 1970s and some new developments were based on scientific research (Duru-Bellat, van Zanten, 2012). For instance, the sociological analyses of Bourdieu and Passeron $(1964,1970)$ were influential in highlighting that although education was transmitting knowledge based on rationality versus ideology, it was reproducing social inequality and contributing to inequalities in educational attainment. On the other hand, the emergence of claims for the assertion of identity from ethnic minorities and religious groups in the sake of individual identity and authenticity (Honneth, 1996) have jeopardized the transmission of a national cultural unicity. Private education and more specifically Catholic education have been attracting intakes from more and more various cultural backgrounds and the Savary law project that intended to merge the state and the private system failed under the pressure of public opinion that considered that having the possibility to choose between different systems was a guarantee for quality and even freedom.

In the 1980 s there was a turn in the use and understanding of secularism. Until then, secularism was opposed to religious power. Things changed with the long-term immigration of Muslims in France. The issue of diversity and the way to manage it in a society growing more and more plural became vivid. The confrontation of populations with different cultural and religious backgrounds raised new challenges. The growing presence of Muslim background students in schools destabilized the partisans of a homogeneous nation fearing a loss of cultural identity. These fears have been the cause of tensions and originated new laws that were meant to protect national identity and to preserve school from specific identity and religious influences. The ban on wearing conspicuous religious symbols in schools by the law of 2004 is part of these new measures. Since the early 2000s, the issue of secularism has taken a new turn in French society. In 1999, the political project to promote the public recognition of the Muslim faith emerged. The French Council for the Muslim Faith was created in 2003. It is a national elected body under the impulsion of Muslim students who claimed for better representation in the political life of the country 
and it serves as an official interlocutor with the French State in the regulation of Muslim religious activities. Created by Nicolas Sarkozy, it was at the time criticized as being the tool for social control reinforcement by part of the State. The very same year, President Chirac created the Stasi commission to reflect upon the principle of secularism and the way it was implemented. One of the issues under discussion was the wearing of the Hijab (Muslim scarf) in state schools (Bergamaschi, 2013) and that originated the ban on wearing conspicuous religious symbols in schools. Cherifi (2005) argues that this measure was counterproductive in the sense that it concerned a small number of individuals and that it contributed to revive the faith of millions of people who were initially moderate but who felt insulted in an important aspect of their religious identity. In 2009-2010, the Ministry for immigration and national identity promoted and organized a huge debate on national identity. This debate took the form of a survey completed throughout France including overseas territories and served two major objectives. The first one was to identify the constitutive elements that make up national identity. The second was to question immigration and more precisely the conditions of residence and the conditions for access to nationality. The purpose was to identify ideas that would help to strengthen the sense of pride for being French (Portail du Gouvernement, 2009). In 2010, the prohibition of face-veiling in public spaces was ratified (French Concealment Act of 11 October 2010) and the debate on alternatives to pork in canteen meals for Muslim children emerged again in the public debate.

All of these measures were widely covered by media and monopolized public debates. The relations between secularism and cultural or religious pluralism are still to be explored. Decision-makers rely on the notion of "positive secularism" to argue that one of the missions of the State is to manage religious pluralism (Campiche, 2015). This is considered as potentially facilitating compatibility between secularism and cultural diversity. Secularism serving to assure neutrality in the public sphere where all individuals could cohabitate happily, provided they do not expose their religious specificities or claim some kind of acknowledgement of their difference. The question "who am I?" then becomes a recurrent refrain among the so-called ethnic minorities for which the concept of "diversity", which results from peaceful and respectful cohabitation of the Other, becomes "difference" and creates a situation where alterity is the target of resistance and identity-related oppositions and even leads to hostility between groups.

To understand how the principle of secularism has become one of the key elements of republican life, it is necessary to look at the role played by the school in perpetuating the political philosophy of the République. 


\section{The French School: a Passionate Link with the République}

As we have seen in the first part of this chapter, school in France is willing to neutralize differences and to convey the idea that all people are equal, regardless of their particular characteristics. This is the quintessence of the Republican identity. Conversely, it must fundamentally disseminate the idea that if one wishes to benefit from the protection of the State, including a relatively flexible procedure for acquiring nationality that, still today, is inspired by jus soli, one must abandon one's peculiarities upon crossing the threshold of its institutions - in this case, school. This seemingly perfect sociological architecture leaves no space for cultural particularisms, because such attachments would deeply contradict the universal interpretation of egalitarianism. This recognition would be to the detriment of a national community that sought to be highly integrated. For example, De Gaulle's cultural levelling policies (Narbonne, 1994) aimed to prohibit the use of dialects in institutional spaces and have been broadly implemented, particularly in the educational system. Thus, at the beginning of the 2oth century, for a student to speak one's one dialect during classes or break times could mean very strict sanctions. In French society there is therefore no room for identity manifestations other than the Republican identity and school is the institution that has been tasked with instilling this idea. It is a very special role that has led some education specialists such as Eric Debarbieux (2008) to suggest that school and the Republic "have a passionate relationship".

It goes without saying that the French society and its educational system have always had a controversial relationship in relation with the issues of "ethnicity" - namely the result of an identity dialectic between groups endowed with unequal economic and cultural resources and whose consequences are variable in contexts (Poutignat, Streiff-Fenart, 2008; Bertheleu, 2007). However, since the foundation of its modern nation, the French society has experienced a major migration influx, which has led to an exponential growth of cultural diversity. France's challenges are, on the one hand, the fact that it has adopted a political philosophy that leaves no space for multi-culturalism and, on the other hand, the fact that it is one of the main European destinations for waves of international migration. Indeed, France was the first country in Europe to use foreign labor, mainly from its (former) colonies, to meet economic and even military requirements (Noiriel, 1988). How can one expect the millions of foreigners who have settled on French soil, and their descendants, to so easily forget their cultural background? How can one believe that the French society is really "indifferent to differences" (Bourdieu, 1966), such as 
those that are generated by such migratory flows? How can all its members thrive in the education system, the labor market and in the urban space? The latest PISA data (2015) are rather stark: among industrialized countries, France is the country where the social origin of individuals has the greatest influence on the educational careers of its students. It is obvious that social origin and migratory origins are two variables that are often closely linked. Despite growing social tensions, where the principles of the Republic are confronted by integration deficits, growing social inequalities and urban segregations lead sociologists to talk about "urban ghettos" (Lapeyronnie, 2009), French institutions continue nevertheless to behave in accordance with the Republican philosophy. Instead of opening up to minimal forms of recognition of cultural diversity and its social implications, measures such as the prohibition of wearing religious symbols in the primary and secondary levels of the school system (Law of 15 March 2004) are designed. In 1989 a student was excluded from high school for the first time due to the wear of Muslim veil. The Minister of National Education at the time, not wishing to face the issue directly, had recourse to the Council of State which reaffirmed the principle of secularism in schools without extending this principle to students. In 1994, wearing ostentatious religious symbols was banned from schools by a ministerial decision. From 2004, school principals have had the right to exclude students wearing headscarves. The dominant position of the politicians and intellectuals were in favor of this measure for three main reasons:

a) to defend the neutrality of the education system;

b) to protect Muslim women from male's domination and patriarchalism;

c) to fight against any religious fanaticism.

Although exclusions from schools were scarce, following this measure, the side effect was to encourage families to lodge complains with the High Authority for Discrimination and Equality (Ichou, van Zantent, 2014). ${ }^{2}$

However, the school system oscillates between taking diversity into account and attempting to neutralize any differences. Some intercultural pedagogy interventions aimed at bringing value to cultural diversity have been implemented since the early 1980 s. There has been a movement that was sporadically diffused under the impetus of teams of very active teachers who strongly believe in the value of diversity. However, this logic of valorization is not without ambiguities since, in the same period of time, there used to be an appointment of non-teaching staff (supervisors, educators, leadership personnel, etc.) according to ethnic criteria (Rinaudo, 1998; Rayou, van Zanten, 2004; Doytcheva,

2 The High Authority for Discrimination and Equality was an independent authority created in 2005 that was dissolved in 2011. 
2007). Thus, an institution that has a high concentration of Maghreb or Black African students would recruit staff who belonged to the same cultural/ethnic groups. The basic idea was that similarity should have helped to manage situations perceived as difficult by the school staffs. However, the problem was that the results obtained were often contrary to expectations and tensions and mistrust between minority students and school staffs increased (Zefir, 2010).

This issue of ethnic diversity is one of the problems that grips the Republican education system, which, like the society that it serves, prefers to adopt the "politics of the ostrich" (De Rudder et al., 200o) rather than rethink its fundamental principles in light of the social changes. However, since the 2000 s we have been witnessing a timid dialogue, starting with the inclusion of secular issues in the training of teachers and principals, and particularly the approach of the inclusive school with the establishment of a Charte de la Laïcité in 2012, followed by a mobilization around the values of the Republic following the terrorist attacks in January 2015 and July 2016. The problem is this idea of secularism is not interpreted in the same way by everybody, and its implementation is oscillating between social hypercontrol of any form of religious expression in the school and a position of dialogue and tolerance. As emphasized by Dubet (2016), secularism is not a disembodied concept that is inculcated. If we promote the idea of shared values, these values must be put into practice by those who contribute to their spreading and therefore be part of their convictions. To think that this is a value shared by all the representatives of the education system remains a utopia and the children who attend the school of the Republic are not socio-cultural idiots.

\section{The Complex Relation between Religion, Schools and Secularism}

As we have just seen, the relationship between religion, secularism and school is particularly complex. The French nation was built in opposition to religion and education is the actor in charge of transmitting and perpetuating a shared and unique national identity. As Schnapper states (2008: 133), given the nation's need to adapt to Republican principles, cultural and religious particularisms are not to be taken into consideration in the public sphere. The French model of integration therefore only recognizes free and equal individuals and "it is in this sense that it can be called universalist and every individual is to acquire their self-worth, independently of the community they belong to" (Hervieu-Léger, 1999: 258).

The high number of people from different ethnic backgrounds in French society and in the educational system questions the relevance of a political 
philosophy rooted in old realities. In particular, as demonstrated by various studies, ethnic minorities are often reminded of their origins -real, supposed, hetero or self-attributed-in several social domains such as labor markets (Silberman, Fournier, 2006; Beauchemin et al., 2010), real estate (Bonnet et al., 2011; Dietrich-Ragon, 2017) and, of course, the education system (Brinbaum, Primon, 2013; Felouzis et al., 2015). In concrete terms, it becomes a form of discrimination that relegates ethnic minorities to underprivileged jobs and neighborhoods and towards educational careers that open up restricted future perspectives. Any attempt from part of these individuals and their communities to reverse the situation and to improve social emancipation is a genuine challenge.

As for education only, the impact of belonging to an ethnic minority on school achievement has been studied expansively in France.

On the one hand, some studies have found that the impact of the ethnic background vanishes once controlled by the socio-economic background of students (Vaillet, Caille, 2001); however, it is also true that the correlation between socio-economic characteristics and ethnic origin is strong and that students, children of immigrants, come mainly from socio-economically deprived backgrounds. On the other hand, more qualitative surveys draw attention to the fact that a significant proportion of these pupils complain of having been victims of some forms of discrimination related to their migratory or cultural origins (Santelli, 2007; 2012). According to Roussier-Fusco (2003) who completed a study in schools in the outskirts of Paris, some teachers' attitudes and behaviors towards students are influenced by the ethnic origin of the latter. In a similar way, other variables are likely to moderate that finding, that is the proportion of ethnic minorities in the class as well as the socio-economical background of the teachers (Perroton, 2000; Rayou, van Zanten, 2004; Sanselme, 2009).

Some other research based on questionnaire surveys and big databases Trajectories and Origins, have recently showed evidence that the ethnic origin of certain groups such as those from the Maghreb, Turkey and sub-Saharan Africa are associated with more problematic schooling experience (e.g. year repetition or school dropout) even after checking on the socio-economic characteristics of the respondents (Brinbaum et al., 2012).

These findings question the capacity of the French universal citizenship model to approach ethnic diversity management without creating hostility and conflicts between the different groups. In order to illustrate the concrete way schools manage diversity, we present the findings of a survey completed in secondary schools in the South of France. The survey aimed to analyze the construction of social relationships among adolescents. More specifically, we 
studied the effect of religious belonging and the way it impacts on the process of developing a sentiment of collective national identity as well as on their school experience.

\section{5}

\section{The Present Study}

Our survey was completed with 2,907 students from junior and high school in the fall of 2017 in south-eastern France. The average age of the respondents was 13.4 for junior students and 16.2 for high school students. There was an equivalent proportion of males and females. We asked the participants to answer questions on their belonging to a religion, if it played an important role in their life, and if they practiced. Our questionnaire also included questions meant to assess their feeling of belonging to the French nation which were drawn from the TEO survey and questions on their school experience in terms of sanctions (how many of them and the perceived reasons behind them, such as skin color, religion, ethnic origin, language spoken). Finally, we tried to assess what their projects were in terms of further education (Blaya, 2019). In our analyses, based on research about the relationship between intolerance and intergroup friendships (Pettigrew, Tropp, 2008), various control variables have been introduced: gender, school level, parents' education level.

\subsection{Descriptive Findings}

We first completed a descriptive analysis of the religious practices of the participants to the survey. Quite a few students answered they did not follow any religion $(37 \%)$, one third stated they were Catholics and one out of five students said they were Muslims. The other potential religions were indicated by under $2 \%$ of the respondents.

The effects of social stratification, measured by the parents' level of education, on belonging to a religion are as follows: young people who declare themselves to be either Christians, or of another religion or without a religion, are more likely to come from families with high educational capital, whereas Muslim youth are concentrated mainly in culturally poorer families where parents gained their compulsory school certificate, vocational certificates or, at best, their diploma from secondary studies (p. ooo $-V .18$ ). The effects of gender are not significant. The importance of religion obtained an average score of $4.1 \mathrm{out}$ of ten points but we noticed differences according to worship: Muslim respondents granted significantly much more importance to religion than the Catholics or the members of other religions ( $M=8,6$ vs. $M=5,1$ vs. $M=5,1)$. Religion proves to be more important for girls ( $\mathrm{p} .000-\mathrm{F} \mathrm{11,3})$ and for the younger 
students (p .000 - F 99,2). As for practicing, half of the students who declared themselves as Muslims reported to be attending a religious service at least once a month, while Catholics were $40.1 \%$ and $10 \%$ from the other religions. The most involved students are the younger ones (p. $\leq .001$ - phi .13), and gender does not make any difference.

The belonging and practice of a religion both depend upon the school capital of the family.

The vast majority of students reported feeling French $(87.3 \%)$ and that the others considered they were French $(78.9 \%)$. The sentiment to be French is stronger among the high school respondents ( $\mathrm{p} . \leq .001-\mathrm{F} 55,2)$ and depends on the level of education of their parents (p. $\leq .001-F 11,6)$. However, this feeling is weaker among the Muslim respondents (p. $\leq .001-F$ 115,7), among those who think that religion is important (p. $\leq .001-\mathrm{F} 44,9)$ and who practice more (p. $\leq$.001 - F 212,2).

As for sanctions in school, boys are more involved than girls (p. $\leq .001-$ F 88,7 ) as well as the students of which parents have low educational background (p. $\leq .001-F 6,9$ ). In the wake of previous studies, we found that Muslim students reported more sanctions than the other students (p. $\leq .001-\mathrm{F} \mathrm{21,3}$ ) as well as the importance they granted to religion (p. $\leq .001-\mathrm{F} 6,1)$ and their level of practice (p. $\leq .001-\mathrm{F} 22,1)$. Many students consider these sanctions reflect discrimination $(\mathrm{M}=5,8)$ mostly Muslim students (p. $\leq .01-\mathrm{F} 5,7)$. The more the students feel religious (p. $\leq .05-\mathrm{F} 2,9)$ and the more they practice, the more they feel they are discriminated (p. $\leq .01-F$ 6,9). We also analyzed the relationship between further education ambitions and religion through a linear regression analysis and our findings show that students who belong to a religion have greater ambitions that the others $(\mathrm{p} \leq .05)$.

\subsection{How Much Do the Young People Feel French?}

It is now interesting to look at the interactions between the factors we have just described in a global explanatory model. More precisely, we have tried to verify how the feeling of being French is affected by, on the one hand, religion and, on the other hand, by school experiences. In that purpose, we ran a multiple linear regression model with stepwise method (Table 24.1). As our study is mainly exploratory, we thought more relevant to identify progressively what were the variables that lead to the model through regressive equations. (Howell, 2006). Our dependent variable is "the feeling of being French", which has been analyzed by mobilizing three sets of independent variables:

a) religion, the importance of the feeling of religiosity, the frequency of participation in religious services; 
TABLE 24.1 The feeling of being French according to the religion and school experiences linear regression, stepwise method $(N=2625)$

\begin{tabular}{|c|c|c|c|c|}
\hline Model & & $\begin{array}{c}\text { Standard } \\
\text { error }\end{array}$ & Bêta & p. \\
\hline $1 \mathrm{P} \leq .001$ & (Constant) & ,032 & & , ooo \\
\hline $\begin{array}{l}\mathrm{R}^{2} .105 \\
\Delta \mathrm{R}^{2} \leq .001\end{array}$ & $\begin{array}{l}\text { Muslim religion } v s \text { any } \\
\text { religion }\end{array}$ & , 075 & 309 & , ooo \\
\hline $2 \mathrm{P} \leq .001$ & (Constant) & ,032 & & , ooo \\
\hline \multirow[t]{2}{*}{$\begin{array}{l}\mathrm{R}^{2} .126 \\
\Delta \mathrm{R}^{2} \leq .001\end{array}$} & $\begin{array}{l}\text { Muslim religion } v s \text { any } \\
\text { religion }\end{array}$ & , 078 & 248 & , ooo \\
\hline & $\begin{array}{l}\text { Frequency of participation in } \\
\text { rites (practicing } v s \\
\text { non-practicing) }\end{array}$ & , 085 & , 186 & , ooo \\
\hline${ }_{3} \mathrm{P} \leq .001$ & (Constant) & ,o6o & & , ooo \\
\hline \multirow[t]{3}{*}{$\begin{array}{l}\mathrm{R}^{2} .138 \\
\Delta \mathrm{R}^{2} \leq .001\end{array}$} & $\begin{array}{l}\text { Muslim religion } v s \text { any } \\
\text { religion }\end{array}$ & , 077 & ,243 & , ooo \\
\hline & $\begin{array}{l}\text { Frequency of participation in } \\
\text { rites (practicing } v s \\
\text { non-practicing) }\end{array}$ & , 085 & , 176 & , ooo \\
\hline & $\begin{array}{l}\text { School level (lower second- } \\
\text { ary school } v s \text { high secondary } \\
\text { school) }\end{array}$ & , o66 &,- 092 & , ooo \\
\hline${ }_{4} \mathrm{P} \leq .001$ & (Constant) & ,o6o & & , ooo \\
\hline \multirow[t]{3}{*}{$\begin{array}{l}\mathrm{R}^{2} .150 \\
\Delta \mathrm{R}^{2} \leq .001\end{array}$} & $\begin{array}{l}\text { Muslim religion } v s \text { any } \\
\text { religion }\end{array}$ &, 078 & ,255 & , ooo \\
\hline & $\begin{array}{l}\text { Frequency of participation in } \\
\text { rites (practicing } v s \\
\text { non-practicing) }\end{array}$ & ,085 & , 168 & , ooo \\
\hline & $\begin{array}{l}\text { School level (lower secondary } \\
\text { school } v s \text { high secondary } \\
\text { school) }\end{array}$ & ,065 &,- 094 & , ooo \\
\hline${ }_{5} \mathrm{P} \leq .001$ & $\begin{array}{l}\text { Other religion } v s \text { any religion } \\
\text { (Constant) }\end{array}$ & $\begin{array}{l}, 129 \\
, 096\end{array}$ & , o8o & $\begin{array}{l}\text {, ooo } \\
\text {, ooo }\end{array}$ \\
\hline $\begin{array}{l}\mathrm{R}^{2} .165 \\
\Delta \mathrm{R}^{2} \leq .001\end{array}$ & $\begin{array}{l}\text { Muslim religion } v s \text { any } \\
\text { religion }\end{array}$ &, 078 & ,245 & , ooo \\
\hline
\end{tabular}


TABLE 24.1 The feeling of being French according to the religion and school experiences linear regression, stepwise method $(N=2625)$ (cont.)

\begin{tabular}{|c|c|c|c|c|}
\hline Model & & $\begin{array}{l}\text { Standard } \\
\text { error }\end{array}$ & Bêta & p. \\
\hline & $\begin{array}{l}\text { Frequency of participation in } \\
\text { rites (practicing } v s \\
\text { non-practicing) }\end{array}$ & , 085 & 166 & , 000 \\
\hline & $\begin{array}{l}\text { School level (lower second- } \\
\text { ary school } v s \text { high secondary } \\
\text { school) }\end{array}$ & , o65 &,- 097 & , ooo \\
\hline & Other religion $v s$ any religion & ,129 & , 078 & , ooo \\
\hline & $\begin{array}{l}\text { Frequency school convoca- } \\
\text { tions / exclusions }\end{array}$ & ,023 & ,o69 & ,ooo \\
\hline
\end{tabular}

b) the frequency of sanctions and temporary exclusions, the feeling of discrimination it may generate;

c) sex, the education capital of the parents, the grade level attended by the student.

Findings show there are five explanatory models, all providing a supplementary and significant explanation compared to the previous model. The first model is based on a single variable that influences the "feeling of being French", namely belonging to the Muslim religion: young people who belong to this religion feel less French compared to peers who reported no religion $(\mathrm{p} \leq .001)$. The second model includes religious practice and young people who attend religious service at least once a month, are characterized by a weaker "feeling of being French" than the students we have defined as non-practicing $(\mathrm{p} \leq .001)$. In a third model shows high school students have a stronger feeling compared to junior school respondents $(\mathrm{p} \leq .001)$. Students who reported they belonged to another religion that is neither Muslim nor Catholic i.e. religions that in our sample are very small, such as the Jewish ( $1.3 \%$ of participants) or the Protestant (1.2\% of participants), show a lower feeling of being French compared to young people without religion $(\mathrm{p} \leq .001)$.

Finally, the more being told off and temporary exclusions are frequent, the weaker is the "feeling of being French" ( $\mathrm{p} \leq$.0o1). The feeling of discrimination as a result of school sanctions and the school capital of parents are not significantly associated to feeling French, nor being Catholic. 
By reading the findings of this survey, the thesis of the "loss of influence" does not seem to be in tune with the picture that is looming. At first, we have seen that the effects of social stratification are consistent with studies that have taken into account the relationship between the ethnic origin, the cultural and religious affiliations, the sense of identification with the national community, and school careers. There is a clear gap between, on the one hand, young people who reported being Muslim and, on the other, young people of other faiths or without any confession at all. This gap can be explained at different levels as fewer cultural resources available within the family, an indicator of minor economic affluence, greater intensity of the feeling of religiosity and a bigger involvement in the religious practice. Secondly, Muslim respondents reported more often being in conflict with the school authority and feeling discriminated. Despite these findings, when analyzing academic ambitions, young people who claim to belong to one of the religions mentioned in the questionnaire, whichever those are, have higher school expectations than the young people who reported being "without religion". Finally, the effects of belonging to the Muslim religion are also apparent in the "feeling of being French", which is weaker compared to young people of either Christian religion, of another faith or without religion. In the same way, this feeling is weaker among the young people for whom religion occupies an important place in life and who participate in religious services at least on a monthly basis. Simon and Tiberj (2012) in the Trajectories and Origins survey showed that the "feeling of being French" fluctuates according to the migratory experiences and the cultural communities. They stress that it would be unfair to conclude that a weak feeling of being French necessarily corresponds to a withdrawal from the mainstream community. According to the authors, it is rather a sign of a society that "is challenging for immigrants and their descendants, to be considered as French". This consideration raises questions and opens the door to a second point from our study, which is the lack of impact of belonging to the Christian religion on the "feeling of being French". In other words, belonging to the Christian faith does not seem to collide with the feeling of belonging to the French identity. We wonder why the membership to the Catholic religion does not trigger the same tensions as the belonging to the Muslim religion, as far as the French identity is concerned. We believe this result deserves a specific analysis throughout history.

As stated in the introduction to this study, it is essential to bear in mind that today "religion plays a role of capital importance in public life and in public action (...) and sheds the perception of it as a vestige from the past" (Moore, 
2007: 413). Thus, religion can be seen as the cultural expression of a given context, allowing it to be presented as one of the elements that contribute to defining identity. It follows from this reading that the notion of the low status of religion in France on the basis of the principles of laity formalized under the Law of 1905 must be reformulated. In order to do this, the historical and anthropological aspects that led to the European process of nation-building should be considered. Jolly (2005) showed that the French sense of laity was paradoxically based on the "confessional grounds" represented by the Catholic faith, which imposed itself over the course of centuries as the "dominant cultural sub-stratus" (Jolly, 2005), overshadowing other minority religions. In France, even more than in other nations, the State was born by staking a clear, official distance from religion. But as Detienne affirms, it is difficult to deny that in the course of contemporary history, Catholicism contributed to consolidating its identity by consecrating the idea of Nation built around a precise cultural memory (Detienne, 2010). According to this perspective, therefore, religion may be the one underlying elements of the social landscape and, though it may not be manifestly vindicated, it can be felt implicitly at precise social conjunctures.

In the last few years, one of the characteristics marking the French political debate and particularly useful to promote France's own sense of identity has been the tacit mobilization of the cultural sub-stratus generated by Catholicism, in its role as one of the constituent elements of "Republican living". Tacit mobilization in this sense refers to the observation that belonging to the Catholic religion emerges only indirectly and, in particular, in negative and contrasting terms with the intention of re-stating what one is not. In this sense, the emphasis on the respect for Republican ideals leads to "identity policies" with manifest effects, like the institution of the Ministère de l'Immigration et de l'Identité Nationale ${ }^{3}$ under Sarkozy's presidency, which promoted the Grand Débat sur l'Identité Nationale ${ }^{4}$ in 2009. One of the consequences of this accent on identity has been to stigmatize groups that have distanced themselves from the principles of the République as a result of their cultural specificity or behavior in the public sphere (Bergamaschi, Santagati, 2019). The group which most often comes "under fire" in these identity policies are Muslims as the results of our study underlined in a sharply way. The incompatibilities in the worldviews characterizing Islam and the Republican model are in fact among the main

3 This Ministry was removed, however, during the government reshuffle in November 2010.

4 The history of the Grand Débat sur l'Identité Nationale can be found on the French Government's web portal: http://www.debatidentitenationale.fr/. 
nodes of French political integration, especially in the last few years. According to Lapeyronnie (2008: 527), the core of the "fight" against Islam involves all sectors of public opinion, since it is associated with "the non-modern or antimodern world of the Other".

In the Fifties, Gordon Allport emphasized the ambivalent role of religion in the process of forming prejudice and stereotypes: "while Faith in the world's major religions is universal and emphasizes the brotherhood of all mankind, in practice it often engenders divisions, which can sometimes be brutal" (Allport, 1954: 6o9). More complex results emerged from Valasik's (2010) analysis of a French sample from the Welfare and Values in Europe survey. In this case, the effects of religion on social and ethical questions appeared to be multidimensional. Depending on the topic under discussion, religion "appears simultaneously as a factor of solidarity and/or discrimination, of tolerance and/ or intolerance, integration and/or xenophobia" (Valasik, 2010: 199). The contours of a multi-dimensional image of religion have become more clearly defined, and the effects appear to take on the guise of a mental map which, according to Willaime (2010: 122), helps to "express a certain conception of man and the world in a given society".

Given these contextual factors, what are the resources French schools have in order to avoid contributing to widening the social gap among young people? We have seen that religious affiliation and the importance attached to it are associated with more chaotic school careers. At the same time, we also know that religious denominations are associated with each other's social hierarchy and, as we have seen, the PISA data point to the difficulties of the Republican school in neutralizing the effects of social stratification on the school experience of students from the most socio-economically deprived backgrounds.

Moreover, young people often consider school difficulties as the result of unequal and discriminatory treatments due to their cultural-religious background. The education system seems to be at the service of one unique and dominant national culture in a perspective of egalitarianism. Nevertheless, the French nation and its education system continue to widen the gap between a so-called majority population -whose profile is in perfect harmony with its principles, even to the point that, in this case, religious affiliation is not a source of tension- and a so-called minority population, increasingly marginalized, and whose basic cultural traits are singled out as the difference par excellence. 